\title{
A relação da linguagem midiática com a teoria da decisão judicial
}

\section{Artur Cesar de Souza}

Universidade de Marília, Programa de Pós-Graduação em Direito, Marília, SP, Brasil ORCID: http://orcid.org/0000-0001-5280-6549

\begin{abstract}
Resumo
Observa-se que a pesquisa da influência dos meios de comunicação em massa na teoria da decisão não pode se sustentar somente em aspectos pragmáticos ou de pesquisa de campo. Há necessidade de uma análise mais acurada em relação à importância da linguagem nessa relação entre mass media e a teoria da decisão. Como pressuposto incondicional de um estudo transparente e de consistência sobre tal influência, é necessário transitar pela concepção da linguagem, assim como indagar qual a sua efetiva importância na relação entre os meios de comunicação de massa e a teoria da decisão. Utiliza-se, para tanto, da metodologia analítica-crítica, e em especial quanto à força do nível perlocucionário da linguagem midiática. Ao final pretende-se demonstrar a efetiva existência dessa influência na teoria da decisão.
\end{abstract}

\section{Palavras-chave}

Mass Media. Meios de Comunicação. Teoria da decisão. Linguagem perlocucionária.

\section{Introdução}

A sociedade brasileira está vivenciando um importante momento de construção de uma nova realidade social decorrente dos efeitos produzidos pela operação criminal denominada de lava-jato. ${ }^{1}$

Além dos aspectos criminais, muito debatidos pela sociedade brasileira, em especial pelos operadores da ciência do direito, um aspecto importante na construção dessa nova

\footnotetext{
${ }^{1}$ Chega-se a tal ponto esta mudança, que o Tribunal Regional Federal da 4⿳a Região houve por bem, como medida de exceção, permitir a transmissão midiática do julgamento proferido pelo ex-presidente da República, Luiz Inácio Lula da Silva.
} 
realidade social é justamente o papel dos meios de comunicação de massa na investigação e divulgação das informações produzidas na referida operação jurídica criminal.

Há muito as ciências sociais vêm analisando os efeitos que os meios de comunicação em massa exercem na construção da realidade social, inclusive na prolação das decisões judiciais.

Ao se ingressar no estudo dos meios de comunicação em massa e da teoria da decisão, o primeiro aspecto a ser considerado é que toda construção da realidade, seja no processo midiático, seja no processo jurisdicional, decorre de um ponto de partida em comum, a linguagem.

Com essa afirmação inicial, pretende-se optar pela perspectiva de que a realidade não tem por fundamentação uma garantia transcendental do conhecimento, dito de outra maneira:

\begin{abstract}
Não podemos comparar nossas proposições supostamente descritivas com um mundo independente da linguagem em que se acha descrito. Pois, segundo Rorty 'não há maneira, como dizia Wittgenstein, de 'introduzir entre a linguagem e seu objeto, de distinguir a girafa em si mesma de nossas maneiras de falar das girafas." (VIVES ANTON, 2007, p. 12).
\end{abstract}

A temática é de uma amplitude incomensurável, razão pela qual, neste singular artigo, pretende-se fazer um corte epistemológico para avaliar a relação que existe entre os meios de comunicação em massa e a filosofia da linguagem como ponto de partida para qualquer estudo que procure identificar os reais efeitos do mass media na decisão judicial.

Portanto, a problemática apresentada, embora tenha por fio condutor a influência da mídia da decisão judicial, restringir-se-á ao diálogo entre os meios de comunicação em massa e a filosofia da linguagem.

\title{
2 A linguagem como experiência do mundo e como construção da realidade social
}

A condição comunicativa do homem, na visão de Mauricio Beuchot (BEUCHOT, 2005), valendo-se dos ensinamentos de Aristóteles (Política), está vinculada à sua natureza social, $\mathrm{e}$ esta à sua natureza racional, a qual evita que ele seja simplesmente gregário como o animal. O homem possui um grande repertório de signos; possui, sobretudo, o signo linguístico, e dele se vale para comunicar a seus semelhantes o que lhe é agradável ou desagradável, o 
que lhe é proveitoso ou nocivo, e, de maneira mais específica, o que considera justo ou injusto.

Na verdade, não existe comunicação sem linguagem, assim como não há linguagem sem comunicação. E não havendo comunicação, não há também o conhecimento da realidade.

Na época antiga, Gorgias de Leontini (484-375) referiu-se de modo clarividente à essência da linguagem, em sua obra Encômio de Helena, afirmando (Beuchot, 2005, p. 13):

La palabra es una gran dominadora, que, con un cuerpo pequeñísimo e invisible, realiza obras por demás divinas". Na perspectiva de Mauricio Beuchot, essa afirmação de Gorgias de Leontini significa que "el lenguaje es tan poderoso que con una palabra más pequeña que una mosca, esto es, con un 'si' o un 'no', puede construir reinos y desatar guerras.

Segundo afirmou Gottfried Herder (1774-1803), em sua obra Sobre o surgimento da linguagem (1772): "A linguagem é muito mais que um instrumento para o manejo da realidade, é, melhor dizendo, algo que constitui a realidade [...]" (BEUCHOT, 2005, p. 145, tradução nossa). Graças à linguagem existe a realidade do "mundo".

Mas a linguagem fechada nos signos e nas relações apenas entre os signos, numa semiótica sem semântica, sem o seu dizer do mundo ou sem referência a ele de qualquer modo que seja, seria um acervo de sinais sem qualquer conteúdo e, portanto, sem qualquer significação possível (NEVES, 2003).

Nestes termos, "se o 'mundo' é pressuposto ontológico da 'realidade' (das coisas e dos acontecimentos), o mundo, enquanto o originário da existência objetivado, emerge de uma unidade objetivante (unidade de uma experiência e da sua expressão) em que participa constitutivamente a dimensão lingüística. É justamente por essa participação constitutiva da linguagem na experiência e no mundo humano que se terá de reconhecer que 'a linguagem é algo diferente de um mero sistema de signos (Zeichensystem) para a designação do todo objetivo' - que 'a palavra não é só signo'. A experiência não se verifica primeiro sem palavras para se tornar depois, por meio de designação, em objeto de reflexão. Pertencem antes à própria experiência o procurar e o encontrar as palavras que a exprimam (NEVES, 2003).

É na linguagem que vem exprimir-se toda a compreensão ôntica ou ontológica do "mundo da vida" (Lebenswelt) (RICOUER, 1969). 
Deve-se, ainda, considerar o caráter comunitário da linguagem, pois ela sempre pertence a uma determinada comunidade linguística, sendo constituída e manifestada por meio de uma comunicação-dialógica nessa comunidade (NEVES, 2003).

É importante salientar que a linguagem não é a língua:

\begin{abstract}
"A linguagem é uma constelação de fenômenos físicos, fisiológicos, psicológicos, sociológicos etc; ao contrário, a língua 'é, por sua vez, um produto social da faculdade da linguagem e um conjunto de convenções necessárias adaptadas pelo corpo social para permitir o exercício desta faculdade nos indivíduos (F. de Saussure). A língua, tampouco é a fala. A língua é o sistema que capacita ou a capacidade que possuem os usuários para construir expressões; a fala é a colocação em exercício de dita capacidade." (BEUCHOT, 2005, p. 175, tradução nossa).
\end{abstract}

A língua e a fala distinguem-se como se distingue o que é social e o que é individual, e o que é essencial e o que é acidental. Saussure afirma que a língua não é uma função do sujeito falante, é o produto que o indivíduo registra passivamente; nunca supõe premeditação, e a reflexão nela não intervém a não ser para classificar. A fala é, pelo contrário, um ato individual de vontade e inteligência, na qual convém distinguir: (I) as combinações pelas quais o sujeito falante utiliza o código da língua com vistas a expressar seu pensamento pessoal; (II) o mecanismo psicofísico que lhe permite exteriorizar essas combinações (BEUCHOT, 2005).

A linguagem, todavia, não é um dado absoluto e neutro, mas um produto cultural que deve ser estudado numa perspectiva histórica e social (TARUFFO, 1975).

Nessa perspectiva cultural, a linguagem não tem por único fim a comunicação das ideias, senão também o de produzir paixões, evitar ações, etiquetar fenômenos (BEUCHOT, 2005).

Segundo Rousseau, em seu livro Ensayo sobre el origen de las lenguas, citado por BEUCHOT :

[...] a linguagem - como a maioria pensa - é para expressar ou comunicar as paixões. Para as necessidades servem mais os movimentos e os gestos [...] Assim, pois, a linguagem não é para expressar nossas necessidades, senão nossas paixões e emoções. Efetivamente, as necessidades não unem os homens, mas os separam e os afastam entre si; ao contrário, são as paixões as que os aproximam. E se a linguagem é para manifestar paixões, isto se faz melhor com a linguagem figurada: para expressar a admiração perante a natureza e seus fenômenos, para abrandar o coração de uma jovem, para provocar ódio ou medo, servem mais os 'tropos' ou figuras de 
linguagem, isto é, a linguagem figurada, que a literal e direta. (BEUCHOT, 2005, p. 139-140, tradução nossa).

Para Giambattista Vico (1668-1774) a natureza da linguagem é mais do que ser um instrumento para a expressão e a comunicação entre os homens; revela algo constitutivo do ser humano, e por isso o acompanha em sua evolução histórica, segundo as diferentes etapas que ele assinala: divina (teocrática e sacerdotal, com idioma sensorial, hieroglífico), heróica (aristocrática, imaginária e simbólica) e humana (monarquia e intelectual) (BEUCHOT, 2005).

Na ótica de Wilhelm von Humboldt (1767-1835), a linguagem é o encarregado da formação do homem, tanto do indivíduo como dos povos. A linguagem intervém na formação das cosmovisões ou visões do mundo. A linguagem é ação, mais que obra, dada sua dinamicidade, que escapa a toda 'esclerotización' ou intento de aprisioná-la (BEUCHOT, 2005).

Na realidade, segundo afirma Harry Pross (1980): “A dependência do homem com respeito às relações entre objeto, signo mediador e consciência interpretante é algo insuperável [...]." (PROSS, 1980, p. 22, tradução nossa).

\section{Duplo sentido do simbolismo discursivo midiático}

A mídia, ao realizar sua comunicação através da linguagem, o faz com base na conjugação de elementos volitivos o afectivos, ou seja, por meio de um duplo sentido ou múltiplo sentido que ao mesmo tempo procura mostrar e ocultar. Esse sentido mostradooculto encontra-se inserido numa estrutura de significação denominada de símbolo, na qual um sentido direto, primário e literal designa acréscimo, outro sentido indireto, secundário e figurado só pode ser apreendido pelo primeiro. Essa circunstância das expressões "[...] de duplo sentido constitui o campo hermenêutico midiático" (SORLIN, 1997, p. 15).

Na realidade, a linguagem dos meios de comunicação em massa não se esgota na informação transmitida, pois ela se engendra em uma série de ressonância e normatização das práticas sociais (WARAT, 1995, p. 15).

A linguagem midiática, longe de se limitar a reproduzir passivamente a realidade tal como ela é, "[...] contribuye activamente a configurarla y, de algún modo, a producirla [...]" (COROMINAS ESCUDÉ, 2000, p. 49). E para produzir de algum modo a realidade social, deve 
fazê-lo por meio de um processo de produção e mutação das significações conotativas (ideológicas) da comunicação social. Assim, o discurso dos meios de comunicação em massa encontra-se vinculado aos diversos setores do todo social (ALTHEIDE, 2005, p. 297).

Essa vinculação, por sua vez, está carregada por uma dimensão político-ideológica que se pode denominar de semiologia do poder ou semiologia política, e que estabelece os pressupostos da produção discursiva a partir de suas ligações com as relações de força da sociedade, bem como pelas determinações ideológicas que a constituem historicamente (ROCHA, 1985, p. 35).

A análise pragmática vinculada à temática ideológica, "[...] impõem a necessidade de realizar leituras ideológicas dos discursos dos meios de comunicação em massa" (WARAT, 1995, p. 47).

As expressões simbólicas passam a ser um mecanismo importante para que os meios de comunicação em massa exteriorizem sua experiência do mundo, sendo que todo esse conteúdo simbólico possui seu advento no elemento da linguagem (SORLIN, 1997).

Para Paul Ricoeur (1969), esse sentido duplo (simbolismo) não representa algo fascinante e, em última instância, mistificante, pois isso é apenas uma questão de lexemas, portanto, de linguagem; a este respeito, o simbolismo nada possui de extraordinário. É uma ilusão pensar que o símbolo, no plano das palavras, seria um enigma, pois a possibilidade do simbolismo está enraizada em uma função comum a todas as palavras, em uma função universal da linguagem, a saber, a aptidão dos lexemas de desenvolver variações contextuais (RICOUER, 1969).

Segundo o filósofo francês, há dois modos de explicar o simbolismo: por aquilo que o constitui e por aquilo que ele quer dizer:

Aquilo que o constitui requer uma análise estrutural; e esta análise estrutural dissipa seu caráter 'maravilhoso'; é a sua função e, ousarei dizer, sua missão; o simbolismo opera com os recursos de toda a linguagem, os quais são sem mistério. Quanto ao que pretende dizer o simbolismo, não é mais uma liguística estrutural que pode ensiná-lo. No movimento de ida e vinda entre análise e síntese, a volta não é equivalente à ida. (RICOUER, 1969, p. 67).

Daí por que a análise do sentido oculto do discurso linguístico produzido pelos meios de comunicação em massa é um pressuposto indispensável para se compreender a construção da realidade social. 
Pela hermenêutica, como trabalho de pensamento, é possível decifrar o sentido oculto inserido no sentido aparente, isto é, desdobrar os níveis de significação implicados na significação literal. Símbolo e interpretação tornam-se assim conceitos correlativos (SORLIN, 1997). É decifrando as astúcias do desejo que se descobre o desejo na raiz do sentido da reflexão.

A tarefa da hermenêutica é a de mostrar que a existência só vem à palavra, ao sentido e à reflexão, procedendo a uma contínua interpretação de todas as significações que se manifestam no mundo da cultura (RICOUER, 1969). A tarefa da hermenêutica é justamente demonstrar essa ambiguidade que por vezes está por detrás do discurso da mídia, esse duplo sentido encontrado no simbolismo midiático.

\section{A retórica como instrumento do discurso linguístico dos meios de comunicação em massa para a delimitação do horizonte hermenêutico ontológico}

O aperfeiçoamento da linguagem possibilitou uma maior adesão ao caráter convencional do significado.

Daí por que conhecer os modos pelos quais as pessoas compartilham ou não conseguem compartilhar os significados por meio do uso da linguagem “[...] é indispensável para compreender como surge a comunicação e quais as suas consequências sobre o público" (DEFLEUR; BALL-ROKEACH, 1995, p. 250).

Ao tempo de Platão, restava muito claro a importância do caráter convencional do significado. Para Platão, a interpretação subjetiva da realidade é uma questão social mais que individual. Segundo o filosófo grego, citado por Defleur e Ball-Rokeach, o conhecimento do mundo no qual vivemos depende não somente disso que percebemos pessoalmente, com os nossos sentidos, mas também pelo fato de que entramos em acordo com os nossos semelhantes em relação a significados condivisos relativos ao mundo externo (DEFLEUR; BALL-ROKEACH, 1995,). Portanto, a "construção social da realidade" não se limita a uma percepção individual meramente sensorial, mas decorre principalmente dos significados condivididos ou acordados socialmente.

E nesse acordo social de significados, a hermenêutica desempenha um papel de suma importância, ao depurar os sentidos ocultos apresentados pelos símbolos linguísticos. 
Os meios de comunicação em massa, cientes desse papel do trabalho interpretativo, utilizam-se muitas vezes do discurso linguístico midiático para delimitar o campo hermenêutico ontológico da construção social da realidade (RICOUER, 1977, p. 17).

Cotidianamente, “[...] somos bombardeados por uma comunicação 'persuasiva' uma atrás da outra. Estas solicitações não convencem por meio do dar e receber argumentações e pelo debate, mas por meio da manipulação dos símbolos e das emoções mais profundas" (PRATKANIS; ARONSON, 1996, p. 15).

Os meios de comunicação, utilizando-se do discurso linguístico de seus textos audiovisuais, seja pela retórica, pela poesia ou pelo erotismo, pretendem nos persuadir, agradar ou seduzir, dando o instrumental necessário para a interpretação do círculo comunicativo ou do círculo semiótico (SILVERSTONE, 2002).

Romper com o campo delimitador desse círculo hermenêutico delineado pelos meios de comunicação em massa passa a ser o grande desafio para se alcançar a neutralização dos efeitos negativos dos mass media.

Especialmente diante das questões criminais, os meios de comunicação em massa, rádio, televisão e jornais, pela retórica, pretendem direcionar a interpretação dos fatos e do direito, sugestionando a opinião pública e de certa forma o próprio juiz do processo (LÓPEZ ORTEGA, 2006).

A retórica torna-se um importante recurso linguístico utilizado pelos meios de comunicação em massa nessa cadeia discursiva, sendo ao mesmo tempo:

\footnotetext{
Uma prática e um instrumento crítico, que permite falar bem e em vista de um escopo, mas também entender e ensinar como fazê-lo do melhor modo possível. Retórica, memória e invenção, inseparavelmente ligadas, num tempo formavam a base de uma cultura pública oral que permitia expressar-se, aumentava a criatividade, notabilizava o pensamento, com o fim de instruir, comover e agradar. (SILVERSTONE, 2002, p. 61, tradução nossa).
}

Acima de tudo, a retórica é persuasão, é delimitação hermenêutica (PRATKANIS; ARONSON, 1996). Trata-se de uma linguagem orientada para ação, com a intenção de alterar posições e orientações e influenciá-la, mas é também voltada para a modificação de valores e comportamentos, a comover ou de todo modo dominar. 
Segundo Roger Silverstone, a linguagem dos meios de comunicação em massa é a retórica, que tem por pressuposto um desejo de influenciar e aceitar a existência de uma hierarquia na estrutura da comunicação midiática (SILVERSTONE, 2002).

Cícero fala de digressão, repetição, redução, hipérbole, atenuação, ironia, indagações retóricas, distinção, correção, preparação do auditório para aquilo que se está para fazer, identificação de parte do público, personificação e assim por diante. Fala, efetivamente, de uma preparação hermenêutica conjugada com a delimitação do campo interpretativo de um determinado fato ou circunstância. Elenca figuras de palavras (repetitio, adiunctio, progressio, revocatio, gradatio, conversio, contrarium, dissolutum, declinatio, reprehensio, exclamatio, imminutio, imago): todos exemplos de "[...] efetiva expressão [...] que são como as armas que se usam para minar e quase para ferir, ou se manejam somente para um espetáculo de beleza" (SILVESRTONE, 2002, p. 68-69).

Como afirma Reinhart Koselleck (2006):

[...] entre as proposições mais chamativas sobre as coisas e uma história linguística que se inclina à permanência, há que registrar, na verdade, um problema geral de toda retórica; esta se constrói sobre argumentos repetíveis para ter efeito num momento singular. Heinrich Lausberg assinalou: Quando os topóis retóricos não são examinados como acontece normalmente, senão de forma singular, ou como algo mal compreendido, então são eles sobrevalorizados; quando, ao contrário, são concebidos como fórmulas vazias e repetíveis, então são eles subestimados, e também são mal-entendidos. 0 que vale para a retórica, vale também para o conjunto da pragmática: trata-se de distinguir entre o conteúdo de inovação e as estruturas de repetição, de sopesar uma e outras para julgar de modo adequado a coisa. Precisamente, a singularidade de um discurso determinado que teve êxito, ou que uma argumentação seja algo único em seu gênero, baseiam-se na arte de usar e combinar elementos repetíveis de linguagem, já conhecidos, de tal maneira que se ouça algo único, ou novo. E para conseguir isso, deve-se sempre ter presente a diferença entre a configuração linguística e o estado objetivo das coisas. A ordem de matar (ou a aprovação do assassinato), ou a notícia da morte não são idênticas à própria morte. (KOSELLECK, 2006, p. 33, tradução nossa).

As raízes da retórica encontram-se no desejo de comunicar pela própria retórica, de alcançar um auditório e identificar-se com esse, mobilizar os lugares comuns unificados pela cultura do tempo e mover-se, criativamente, para além desses. Os lugares comuns são, de fato, lugares de invenção e inovação tanto quanto de memória e de testemunhança (SILVERSTONE, 2002,). 
Examinar os discursos linguísticos dos meios de comunicação em massa do ponto de vista retórico significa compreender como os significados são construídos e adaptados de modo plausível, agradável e persuasivo.

\section{0 nível perlocucionário do discurso dos meios de comunicação em massa}

Atualmente, é aceito nos gabinetes editoriais que o objetivo dos jornais, dos discursos ou dos programas de rádio e de televisão não é o de simplesmente transmitirem informações ou difundirem opiniões (SORLIN, 1997).

A linguagem dos meios de comunicação vai mais além da transmissão e difusão de opiniões. Na verdade, a linguagem dos mass media preenche três funções: (1) a função da reprodução cultural ou da presentificação das tradições (é nessa perspectiva que Gadamer desenvolve sua hermenêutica filosófica); (2) a função de integração social ou da coordenação dos planos de diferentes atores na interação social (é nessa perspectiva que se desenvolve a teoria do agir comunicativo), e (3) a função da socialização da interpretação cultural das necessidades (é nessa perspectiva que C. H. Mead projetou sua psicologia social) (HABERMAS, 2003).

Para Maurice Mereleau-Ponty, a linguagem sempre apresenta uma tripla função: (1) função representativa; (2) função expressiva; (3) função de apelo ao outro (MERLEAUPONTY, 1990).

Assim, pode-se a firmar que "dizer algo a alguém" e "compreender o que é dito" baseiam-se em pressuposições mais complicadas e muito mais pretensiosas do que o simples “dizer (ou pensar)” (HABERMAS, 2003).

Mais uma vez o alerta deve ser feito, pois não se deve confundir os signos da linguagem, que só remetem a outros signos no interior do mesmo sistema e fazem com que a língua não possua mais mundo, como não possui tempo e subjetividade, com o discurso linguístico que é sempre discurso a respeito de algo: refere-se a um mundo que pretende descrever, expressar ou representar e estabelecer os limites de sua interpretação. (RICOUER, 1977).

Enfim, a língua não é senão a condição prévia da comunicação, para qual ela fornece seus códigos; mas é no discurso que todas as mensagens são trocadas (RICOUER, 1977). 
O discurso se dá como evento, pois algo acontece quando alguém fala. Essa perspectiva de discurso como evento ocorre a partir do momento em que se realiza a passagem de uma linguística da língua ou do código a uma linguística do discurso ou da mensagem. A distinção advém de Ferdinand Saussure e Louis Hjelmslev. 0 primeiro distingue a "língua" e a "fala"; o segundo distingue o "esquema" e o "uso" (RICOUER, 1977).

Afirmar que o discurso é um evento significa dizer que ele é realizado temporalmente e no presente. 0 evento, nesse sentido, é a vinda à linguagem de um mundo mediante o discurso. É no discurso que todas as mensagens são trocadas. Nesse aspecto, o discurso possui não somente um mundo, mas o outro, outra pessoa, um interlocutor ao qual se dirige. Nesse aspecto. o evento é fenômeno temporal da troca, o estabelecimento do diálogo, que pode travar-se, prolongar-se ou interromper-se (RICOUER, 1977).

Ao se mencionar o caráter do evento do discurso, apenas se revelou um dos dois polos de sua constituição.

O segundo aspecto importante do discurso é o da significação.

É a tensão entre esses dois polos (evento e significação) que configura o discurso como obra, a dialética da fala e da escrita.

Na verdade, segundo Paul Ricouer (1977), todo discurso é efetuado como evento e compreendido como significação. 0 que se deseja compreender não é o evento, à medida que é fugidio, mas sua significação que permanece. Essa articulação é o núcleo de todo o problema hermenêutico.

Para conseguir elucidar o que "é dito" de modo mais completo, a hermenêutica deve recorrer não somente à linguística - mesmo compreendida no sentido de linguística do discurso, por oposição à linguística da língua - mas também à teoria do speechact, encontrada em John Langshaw Austin e em John Searle. 0 ato do discurso, segundo esses autores, é constituído por uma hierarquia de atos subordinados, distribuídos em três níveis:

[...] 1) ao nível do ato locucionário ou proposicional: ato de dizer; (2) ao nível do ato (ou força) ilocucionário: aquilo que fazemos ao dizer; (3) ao nível do ato perlocucionário: aquilo que fazemos pelo fato de falar. "Se eu digo a alguém para fechar a porta, faço três coisas: (a) refiro o predicado de ação (fechar) a dois argumentos (alguém e a porta): ato de dizer; (b) mas eu digo essa coisa a alguém com a força de uma ordem e não de uma constatação, de um desejo ou de uma promessa: é o ato ilocucionário; (c) enfim, posso provocar certos efeitos, tais como o medo, pelo fato de dar uma ordem a alguém; esses efeitos fazem do discurso uma espécie de estímulo que produz certos resultados: é o ato perlocucionário. (RICOUER, 1977, p. 47-48). 
Segundo Paul Ricouer (1977), o ato perlocucionário constitui o aspecto menos inscritível do discurso, e caracteriza, preferencialmente, o discurso oral. Na sua visão:

A ação perlocucionária é justamente aquilo que, no discurso, é o menos discurso. É o discurso enquanto estímulo. Neste caso, o discurso manifesta-se não pela trucagem do reconhecimento, por meu interlocutor, de minha intenção, mas, de certa forma, de um modo energético, por influência direta sobre as emoções e as disposições afetivas do interlocutor. Assim, o termo significação tem uma acepção bastante ampla, recobrindo todos os aspectos e todos os níveis da exteriorização intencional que torna possível, por sua vez, a exteriorização do discurso na obra e nos escritos. (RICOUER, 1977, p. 48-49).

Segundo Mauricio Beuchot (2005), baseando-se em John Langsbaw Austin (19111960):

Toda manifestação linguística é um ato que envolve outros três atos como dimensões suas: é, por sua vez, um ato locucionário, um ato ilocucionário e um ato perlocucionário. A dimensão de ato locucionário é a mais primitiva e elementar; dá-se na expressão linguística enquanto esta possui certo sentido e certa referência. Logo vem a dimensão de ato ilocucionário, que é mais elaborada e se dá na expressão linguística enquanto esta possui uma força característica, segundo o tipo de intenção que a anima: asseverar, ordenar, desejar, advertir etc. Finalmente aparece a dimensão de ato perlocucionário, que se dá na expressão linguística enquanto ela produz certo efeito psicológico no ouvinte: informa-o, persuade-o, não o persuade, inclusive o surpreende ou lhe desconcerta. (BEUCHOT, 2005, p. 250, tradução nossa).

Os meios de comunicação em massa, ao realizarem seu discurso linguístico sobre determinados fatos, o fazem sob a égide dos níveis locucionários, ilocucionários e principalmente perlocucionários.

Pelo nível perlocucionário pretendem provocar, por meio da retórica, certos efeitos, seja na opinião pública, seja no juiz do processo, entre eles o efeito medo ou paúra na opinião pública e o efeito irresponsabilidade ou conivência à impunidade no juiz.

Na verdade, o nível perlocucionáro do discurso midiático pode atingir, acima de tudo, aquilo que Lacan denomina de inconsciente coletivo (MUÑOZ, 1989).

A figura do "inconsciente coletivo" de Lacan nos sugere uma pergunta que não quer calar: se se poderia aplicar a prática psicanalítica de Lacan às "fantasias mass midiáticas" com a finalidade de se encontrar uma possível patologia coletiva difundida, dia a dia, e 
repetida, ano a ano, por meio de uns significantes (e símbolos) muito bem elaborados? (MUÑOZ, 1989).

Empiricamente pode-se constatar, de certa forma, a importância do nível perlocucionário no inconsciente coletivo. Na análise estatística feita na Itália por Gerlinda di Smaus (1978), referente à sensação de insegurança e do aumento da criminalidade, observa-se que $71 \%$ dos entrevistados têm a impressão de que a criminalidade encontra-se em franca ascensão, apesar de não coincidir a sensação coletiva com os dados oficiais sobre a criminalidade (SMAUS, 1978).

No Brasil, essa sensação de constante aumento generalizado da criminalidade também está enraizada no "inconsciente coletivo" em decorrência do efeito perlocucionário do discurso retórico linguístico midiático.

Segundo David L. Altheide(2005):

Existem duas razões pelas quais o crime está tão propagado na televisão americana e, de modo crescente, em todo o mundo. A primeira, como dito, é que o crime está conexo ao medo, sendo a melhor parte dos formatos de entretenimento. A segunda é que o crime é muito fácil de se tratar e por isso se adapta bem à programação e às limitações pessoais das televisões locais: como observou o vice-presidente de uma rede de televisões locais, 'as notícias sobre o crime são as mais fáceis, as mais velozes, as mais econômicas, as mais eficazes para as televisões. Os novos diretores amam o crime [...]. Um claro limite desta estrutura é que os crimes mais raros, como homicídio e lesões graves, recebem a maior parte do espaço informativo, enquanto aqueles mais frequentes, como furtos e roubos, são pouco tratados. Como consequência, os expectadores (e os leitores) têm a impressão de que crime significa necessariamente 'crime violento'. Está amplamente provado que esta percepção do 'problema criminal' encoraja o eleitor a defender 'legislações repressivas', como a obrigação de condenações severas após o terceiro crime cometido (three strikes and you are out) e a pena de morte. (ALTHEIDE, 2005, p. 289, tradução nossa).

Mas para que o discurso linguístico midiático possa alcançar sua pretensão perlocucionária, não é suficiente apenas a hipervaloração quantitativa e qualitativa dos fatos delituosos. 0 medo (paúra) não é decorrente apenas dessa inconsistência informativa.

Para que a pretensão midiática tenha algum sucesso, é necessário que esteja presente na opinião pública um importante fator de acoplamento que é a necessidade do cidadão colocar-se em lugar do outro, isto é, no lugar da vítima de um crime massificadamente transmitido pelos mass media (ALTHEIDE, 2005). Na verdade, "[...] quanto mais frequentemente os telespectadores vejam representações da violência, tanto mais percebem 
a probabilidade de se transformarem em vítimas de ações violentas[...]." (KURY, 2005, p. 346, tradução nossa).

A experiência do crime, da dor e do ressentimento provocado pelo fato delituoso, de colocar-se em lugar do outro (vítima do delito), corresponde àquilo que Max Scheler denominará de proximidade da consciência coletiva:

[...] as consciências só são separadas pela sua corporeidade, pelo conjunto dos instrumentos de que se servem; a 'corporeidade' é de certo modo a matéria sensível com a ajuda da qual se apreende a si mesmo ou ao outro. Mas o sensível puro num conteúdo, sua intenção, pode ser compartilhado pelo outro. Assim, numa queimadura, só o sujeito que se queima pode sentir a acuidade sensível da dor; mas tudo o que uma queimadura representa - ameaça do fogo, perigo para a integridade do corpo, o sentido de dor - pode ser comunicado ao outro e sentido pelo outro; é então a mesma forma, o mesmo conteúdo do sentimento que é vivido por meio de outra matéria. 0 sentido, a intenção do sentimento (o que constitui o essencial deste) é semelhante para as duas consciências; há isolamento do sentido mas não isolamento de consciências (MERLEAU-PONTY, 1990, p. 50).

Segundo Scheler, não se pode realmente ser o outro, mas pode-se tornar o outro intencionalmente, pode-se atingir o outro por meio de suas manifestações expressivas pelas quais ele se dá a nós. Na dor não se percebe o outro enquanto não se representa para si sua dor material e sensível; o elemento intencional do sentido só é generalizado em relação ao sentimento verdadeiro. Não se tem a experiência real do outro enquanto não se ligam as significações de um sentimento ao fato mesmo de viver essas significações (MERLEAUPONTY, 1990).

Como já teve oportunidade de advertir Alessandro Baratta (1983:

0 medo da criminalidade representa um sentimento geral de insegurança e de ansiedade não ligado apenas aos fenômenos criminais e, de todo modo, relativamente independente da específica percepção da possibilidade de se transformar em vítima dos delitos no próprio quarteirão. A desproporção entre o medo genérico da criminalidade e a valoração do perigo concreto de se transformar em vítima de delitos (nítida vantagem do primeiro) resulta também pela já recordada pesquisa sobre a reação social ao comportamento desviante etc.(BARATTA, 1983, p. 25, tradução nossa).

Portanto, é pela sensação de medo (paúra) acoplada ao receptor - colocar-se em lugar do outro - que o efeito perlocucionário pretendido pelos meios de comunicação em massa terá eficácia no âmbito da "opinião pública". 
Contudo, o mais preocupante é que os resultados obtidos pelo nível perlocucionário do discurso midiático no "inconsciente coletivo" (sensação de aumento da criminalidade, medo, paúra) não se restringem ao âmbito da opinião pública.

Os efeitos do nível perlocucionário do discurso linguístico dos mass media podem desencadear consequências em "cascata" extremamente drásticas, isto é, produzir um mecanismo social de pressão no resultado do processo jurisdicional, a fim de que a sentença a ser proferida no âmbito do juízo criminal tenha correspondência à delimitação hermenêutica traçada previamente pela retórica discursiva proveniente dos mass media.

Por meio de mecanismo intimidador decorrente do nível perlocucionário, pretende-se transferir ao Poder Judiciário a responsabilidade por eventual sensação de aumento da impunidade, quando a decisão não esteja em conformidade aos limites hermenêuticos traçados no discurso midiático.

Os riscos para um processo público com todas as garantias são importantes, principalmente pelo fato de que os limites hermenêuticos estabelecidos pelos meios de comunicação em massa e introduzidos no âmbito do nível perlocucionário de seu discurso não apresentam qualquer compromisso com a verdade ou falsidade, pois o código binário dos mass media está circunscrito ao informar ou não informar.

\section{Conclusão}

Procurou-se evidenciar neste trabalho a importância da linguagem na relação existente entre mass media e a ciência jurídica, em especial, a decisão do juiz no processo jurisdicional criminal.

Após um transcurso teórico sobre os principais fatores de composição da linguagem, chega-se à conclusão que os efeitos do nível perlocucionário do discurso linguístico dos mass media pode desencadear consequências em "cascata" extremamente drásticas, isto é, produzir um mecanismo social de pressão no resultado do processo jurisdicional, a fim de que a sentença a ser proferida no âmbito do juízo criminal tenha correspondência à delimitação hermenêutica traçada previamente pela retórica discursiva proveniente dos mass media.

Essa constatação é, sem dúvida, um fator preponderante para qualquer estudo referente à influência dos meios de comunicação em massa na teoria da decisão. 


\section{Referências}

ALTHEIDE, David. L. I mass media, il crimine e il 'discorso di paura'. In: FORTI, Gabrio; BERTOLINO, Marta(org). La televisione del criminine. Milano: V\&P Università, 2005.

BARATTA, Alessandro. Problemi sociali e percezione della criminalità. Dei delitti e delle pene. Rivista di Studi Sociali, Storici e Giuridici Sulla Questione Criminale, Roma, ano I, n. 1, genn. - apr., 1983.

BEUCHOT, Mauricio. História de la filosofia del lenguaje. México: Fondo de Cultura Económica, 2005.

COROMINAS ESCUDÉ, Jordi. Ética primera:Aportación de X. Zubiri al debate ético contemporáneo. Bilbao: Desclée de Brouwer, 2000.

DEFLEUR, Melvin L.; BALL-ROKEACH, Sandra J. Teorie delle comunicazioni di massa. Bologna: Il Mulino, 1995.

HABERMAS, Jürgen. Consciência moral e agir comunicativo. Rio de Janeiro: Tempo Brasileiro, 2003.

KOSELLECK, Reinhart. Estructuras de repecticón en el lenguaje y en la historia. Revista de Estudios Políticos, Madrid, n. 134, dic. 2006.

KURY, Helmut. Mass media e criminalità: l'esperienza tedesca. In: FORTI, Gabrio; BERTOLINO, Marta (org). La televisione del crimine. Milano: V\&P Università, 2005.

LÓPEZ ORTEGA, Juan J. Información y justicia. In: Justicia y medios de comunicación . Madrid: Consejo General del Poder Judicial, 2006. (Colección Cuadernos de Derecho Judicial. Justicias y Medios de Comunicación).

MERLEAU-PONTY, Maurice. Merleau-Ponty na Sorbonne: resumo de cursos. Campinas: Papirus, 1990.

MUÑOZ, Blanca. Cultura y comunicación: - Introducción a las teorías contemporáneas. Barcelona: Barcanova, 1989.

NEVES, Antonio Castanheira. 0 actual problema metodológico da interpretação jurídica. Coimbra: Coimbra Editora, 2003.

PROSS, Harry. Estructura simbólica del poder: - Teoría y práctica de la comunicación pública. Barcelona: Gustavo Gili, 1980.

RICOUER, Paul. Interpretação e ideologias. Rio de Janeiro: Francisco Alves, 1977.

RICOUER, PAUL. 0 conflito das interpretações: - Ensaios de hermenêutica. Rio de Janeiro: Imago, 1969. 
ROCHA, Leonel Severo. A problemática jurídica: uma introdução transdisciplinar. Porto Alegre: Fabris, 1985.

SILVERSTONE, Roger. Perché studiare i media? Bologna: Il Mulino, 2002.

SMAUS, Di Gerlinda. L'immagine della criminalità nei mass media contenuti e significati simbolici. La Questione Criminale - Rivista di Ricerca e Dibattio su Devianza e Controllo Sociale, Bologna, ano IV, n. 1, genn.-apr. 1978.

SORLIN, Pierre. Mass media. Londres: Celta, 1997.

TARUFFO, Michele. La motivazione della sentenza civile. Padova: Cedam, 1975.

VIVES ANTÓN, Tomás S. Más allá de toda duda razonable. Teoria y Derecho - Revista de Pensamento Jurídico, Valencia,. n. 2,jun.-dic. 2007.

WARAT, Luis Alberto. 0 direito e sua linguagem. Porto Alegre: Fabris, 1995.

\title{
The relationship of media language with the theory of judicial decision
}

\begin{abstract}
It is observed that the research of the influence of the mass media in the theory of decision cannot be sustained only in pragmatic or field research aspects. There is a need for a more accurate analysis in relation to the importance of language in this relationship between the mass media and the theory of opinion. As an unconditional assumption of a transparent and consistent study of this influence, it is necessary to move through the conception of language, as well as to inquire about its effective importance in the relationship between the mass media and the theory of decision. For this, the analytical-critical methodology is used, and especially as regards the strength of the perlocutionary level of the media language. In the end, we intend to demonstrate the effective existence of this community of decision theory.
\end{abstract}

\section{Keywords}

Mass Media. Media. Decision theory. Perlocutionary language.

\section{Autoria para correspondência}

Artur Cesar de Souza

artur.souza@trf4.jus.br 


\section{Como citar}

SOUZA, Arthur Cesar de. A relação da linguage,midiática com a teoria da decisão judicial. Intexto, Porto Alegre, n. 52, e-80322, jan./dez. 2021. DOI: http://dx.doi.org/10.19132/1807-8583202152.80322

Recebido em 14/02/2018

Aceito em 18/04/2019 